\title{
South Korean Teachers' Perceptions of Integrating Information and Communication Technologies into Literacy Instruction
}

\author{
Sangho Pang, ${ }^{1}$ David Reinking, ${ }^{1}$ Amy Hutchison, ${ }^{2}$ and Deanna Ramey ${ }^{1}$ \\ ${ }^{1}$ Eugene T. Moore School of Education, Clemson University, Clemson, SC 29634, USA \\ ${ }^{2}$ School of Education, Iowa State University, Ames, IA 50011, USA \\ Correspondence should be addressed to Sangho Pang; spang@clemson.edu
}

Received 5 August 2014; Revised 4 January 2015; Accepted 7 January 2015

Academic Editor: Eduardo Montero

Copyright (c) 2015 Sangho Pang et al. This is an open access article distributed under the Creative Commons Attribution License, which permits unrestricted use, distribution, and reproduction in any medium, provided the original work is properly cited.

\begin{abstract}
We investigated South Korean literacy and language arts teachers' perceptions about integrating interactive communication technologies (ICTs) into instruction. The survey addressed their access to various applications and technologies associated with ICTs, access to technological support, frequency and importance of use, and obstacles to and conceptions of integrating ICTs. Descriptive and correlational data are reported suggesting that although classroom use of ICTs is mandated at the national level, South Korean teachers perceive access to some tools and applications, as well as the availability of technical assistance at both the school and district level, to be limited. We compare data from this study to our findings from a similar study conducted in the USA and discuss what the findings reveal about integration of ICTs into literacy instruction in South Korea. The implications for education policy in South Korea and for continued research to clarify findings across national and cultural boundaries are discussed. For example, despite reporting greater impact of obstacles and less technical support than their US counterparts, South Korean teachers reported using ICTs more frequently than teachers from the USA.
\end{abstract}

\section{Introduction}

The integration of information and communication technologies (ICTs) into the curriculum and instruction of formal schooling has global implications and dimensions [1-3]. As ICTs continue to evolve rapidly and to become more prevalent in daily life, including the workplace, there is an increasingly strong imperative for educators worldwide to seek ways to promote that integration [4] and to understand the dynamics of how it does or does not occur and why [5]. It is also clear that understanding the extent of integration and how it is better achieved depends as much on sociocultural factors (e.g., [6]), including teachers' beliefs [7], as it does on the availability of relevant technologies and expertise.

In the study we report here, our goal was to further such understanding by conducting a national survey of literacy and language arts teachers in elementary, middle, and secondary schools in South Korea. The survey was designed to determine their reported integration of ICTs into literacy and language arts instruction, to characterize their beliefs about the importance of doing so, and to identify the obstacles they perceived as hindering increased integration. Our main purpose was to generate data that would identify broad conditions, trends, issues, and perspectives that reflect the broad contextual landscape of South Korean teachers' efforts to integrate ICTs into instruction. Such data are a useful, and perhaps necessary, first step laying the ground work for more focused work probing deeper explanation through interviews and observations in classrooms. Another purpose was to generate data that may be useful to policy makers and others, such as those involved in professional development, who wish to systematically increase the integration of ICTs into instruction in South Korea.

Replicating in South Korea our related work in the USA also helps clarify issues of technology integration across national and cultural borders. Specifically we investigated the following questions. (a) What technologies and technical support related to integrating ICTs do literacy teachers in South Korea report are available to them? (b) How frequently do they report using various ICTs and applications in their 
instruction and how important do they perceive them to be? (c) What obstacles to integrating ICTs do they report? (d) What do respondents identify as most representative of integrating ICTs into instruction? (e) What noteworthy patterns or relations might be suggested when comparing factors such as levels of integration, perceived obstacles to integration, and beliefs about the importance of integrating ICTs? (f) How do South Korean teachers' reported use and perceptions compare to those of US teachers in our previous work?

We focused on literacy and language arts teachers for several reasons. First, to an extent greater than teachers in other school subjects, literacy and language arts teachers face a more fundamental transformation of perspectives, content, and approaches if ICTs are to be assimilated into instruction [8]. Shifting their teaching away from conventional printbased materials toward digital forms of textual information and communication suggests deep substantive changes in content and orientation and perhaps some resistance, given the cultural capital frequently associated with printed materials, particularly books in many cultures, and thus moving into what has been called a posttypographic era $[9,10]$. Second, language arts are the logical area of the existing curriculum for developing the new skills, strategies, and dispositions necessary for contending successfully with ICTs and new forms of reading, writing, and accessing information [11]. Third, our research replicates a parallel study in which information was collected from a large sample of literacy and language arts teachers in the USA, providing an interesting point of comparison in another culture and system of education [12, 13].

South Korea is representative of several East Asian countries that are at the forefront of technological change and may be indicative of important cultural changes in East Asian society and education in particular. For example, Richards [14] argued that ICTs, but particularly the Internet,

...represents a force of cultural change in both education and society in terms of informal as well as institutional contexts and imperatives. Nowhere is this more evident than in East Asian countries extending from Korea and Japan down to Singapore and Thailand, and. ..China (p. 338).

Thus, in addition to being useful to educators and policy makers in South Korea, education researchers in the USA may be enlightened by data regarding teachers' beliefs and perspectives collected from a country representative of East Asian culture, where ICTs may entail significant societal and educational changes.

\section{Theoretical and Empirical Rationale}

Several related premises, derived from the existing theoretical and empirical base, support the rationale for our line of research studying the extent to which ICTs are being integrated into literacy and language arts instruction. For example, there is considerable theoretical support for the premise that printed and digital texts offer substantively different affordances to writers and readers, thus altering conceptions of literacy and, in turn, the teaching of the language arts. Several literacy scholars have illustrated and explicated theoretically, through several periods of technological development and change, how the affordances of digital reading and writing alter fundamental assumptions about reading and writing derived from conventional printed texts [15-20]. For example, that literature supports the contention that, compared to printed texts, digital texts are literally interactive, multimodal, nonlinear, and responsive to readers' needs and enable more freedom and control in accessing textual information. It is well established in the literature that these different affordances and the development of new forms, genres, and purposes for written communication fundamentally alter conceptions of literacy and how it is developed (e.g., [2, 21, 22]).

Based on these new conceptions of literacy, literacy instruction should involve the use of ICTs for both reading and writing digital texts [23]. For example, literacy instruction might include opportunities for students to read upto-date information online about timely news topics and postinformed opinions on the topic to a blog or social networking site as a means of engaging in a conversation with others outside the classroom. Similarly, students may create videos to illustrate their understanding of a topic or share their opinions with a global audience. Additionally, to change literacy instruction to match new conceptions of literacy, Knobel and Lankshear [24] argue that teachers themselves need experience and understand what it means to be engaged in digital literacy practices.

A second theoretical premise is that reading digital texts requires different skills, strategies, and dispositions compared to reading and writing conventional printed texts. A prominent example is the Internet, which requires unique strategies for locating (e.g., [25, 26]) and evaluating [27] information. Supporting this premise is the low correlation between assessments of reading comprehension of printed texts when compared to similar textual information presented digitally on the Internet [28]. This second premise leads logically to a third related premise: language arts teachers, and by extension, administrators and policy makers have a responsibility to ensure integration of ICTs into the curriculum and instruction toward developing literacy skills, strategies, and dispositions necessary for success in a world where printed texts are no longer dominant $[2,13,23]$. Put succinctly, conceptions of literacy and literacy instruction developed in the 20th century are no longer sufficient to prepare students for literacy in the 21st century. Thus, it is important to understand and monitor how teachers are responding to this shift, particularly language arts teachers, who bear the most responsibility for developing students' literacy.

A fourth theoretical premise justifying our interest in understanding and monitoring the integration of ICTs into language arts instruction is that educators, and those who conduct research that might inform them are not adequately responding to the shift from printed to digital texts and to the new communication technologies responsible for that shift. That is, this premise that is widely shared is reflected in the stances of professional organizations dedicated to promoting 
literacy and the highest standards of literacy instruction. For example, the International Reading Association [29, 30] has adopted a position statement based on the following stance:

To become fully literate in today's world, students must become proficient in the new literacies of 21st-century technologies. As a result, literacy educators have a responsibility to effectively integrate these new technologies into the curriculum, preparing students for the literacy future they deserve [30, n.p.].

Likewise, the National Council of Teachers of English (NCTE) has four position statements, four sets of guidelines, and 11 resolutions related to ICTs, including standards for integrating them into instruction (see http://www.ncte.org/).

Supporting these theoretical premises is evidence that ICTs are not being sufficiently integrated into language arts instruction $[11,31,32]$ or that they are being implemented superficially in what we have termed technological rather than curricular integration [12]. That is, literacy and language arts teachers in the USA tend to perceive simply using digital technologies as integration of ICTs rather than adopting new curricular goals and creating instructional activities aimed at developing 21st century literacy skills, although they do acknowledge the importance of acknowledging new dimensions of literacy. We wondered if literacy and language arts teachers in South Korea would have similar perceptions.

Finally, our work conducting surveys with teachers about integrating ICTs into instruction is guided by a theoretical model about the role of teachers' perceptions and beliefs in determining how and to what extent ICTs are integrated into instruction. Hutchison and Reinking [12] developed and tested that model using path analysis to model the relationship among teachers' perceptions about the importance of integrating ICTs into literacy instruction and the extent to which teachers actually integrate ICTs into instruction. The model suggested that teachers' perceptions of the importance of ICTs directly influence the extent to which they integrate ICTs. Their model also reflects the sociocultural factors that influence whether or not teachers attend to the affordance of ICTs in the classroom. Other longstanding empirical evidence also supports the premise that sociocultural contexts such as access to ICTs; instructional planning time; availability of technical support; familiarity with ICTs; and school and district stance on ICT integration, impact teacher decisions regarding integration of digital technologies into instruction [7, 33-37]. The majority of that research has been conducted in the USA, although similar trends have been found in other countries and areas of the world (e.g., [38]). For example, in a case study of primary school teachers in Singapore, Lim and Chai [39] found that though five of the six teachers in the case held pedagogical beliefs embracing the affordance of ICTs, most of their ICT-mediated lessons contained some traditional element such as drill and practice. The teachers, aware for the most part that they were not making full use of the ICTs' accommodations, attributed their actions to their sociocultural context; naming factors such as an examination oriented society, block scheduling, fixed curriculum, and issues with classroom management. More research is warranted, not only to characterize how ICTs are being integrated into instruction in diverse countries and cultures, but also to determine the extent to which perceptions are grounded in cultural and contextual differences or the extent to which they may emanate more broadly from generic aspects of technologies and their affordances and uses.

\section{Context of ICTs in South Korean Education}

The present study and its findings are better understood within the context of education in South Korea. South Korea has been identified as an example of rapid progress in upgrading its educational system since the mid-20th century [40]. In the mid-1990s an educational reform commission organized by former president Kim Young Sam created a blueprint for education reform in what became known as the 5.31 Education Reform Proposals (ERP). As a result of ERP plans and in line with the First ICT Master Plan for South Korea initiated in 1996, ambitious school-enhancement policies were enacted, infusing state-of-the-art technology into classrooms [41-43]. As a result, South Korea became one of most advanced countries in Asia with regard to integrating ICTs into the education system [44]. It ranked first in computer infrastructure and use among countries included in a survey conducted by the Organisation for Economic Cooperation and Development [45].

Almost all South Korean classrooms have been equipped with high-speed Internet connections since 2002, and computers and other related technologies for instruction have been rapidly integrated into curriculum under the policies of the Ministry of Education [44], which, as in other Asian countries, exerts influential, centralized control. These policies include curricular guidelines and standards pertaining to ICTs that the Ministry of Education Science and Technology (MEST) introduced in 2000 and updated twice [46-48]. Government policy requires teachers in every subject to incorporate ICTs into at least $10 \%$ of classroom activities [49]. Yet, the authors of a recent study express concern that important skills related to ICTs are not being accomplished in South Korea [1]. Although reforms initiated in the mid-1990s focused on integrating ICTs into education, the emphasis more recently has shifted toward creating a new culture of learning that is less teacher-centered and more selfdirected $[41,50]$. Nonetheless, pressures continue on teachers to prepare students to pass a college entrance exam that assesses specific knowledge. One purpose of this study was to investigate broadly whether these initiatives have effected integration of ICTs into instruction, and how they are viewed among literacy teachers. Are policy initiatives based on infusions of technology and centralized curricular mandates sufficient promote integration?

\section{Method}

This investigation employed survey methodology, an established, if not common, methodology in literacy research [51]. In this section we describe the survey used in this study, how it was developed and disseminated to respondents, and how we analyzed the data it generated. 
TABLE 1: Grade level, age, teaching experience, and region of respondents.

\begin{tabular}{|c|c|c|c|c|c|c|c|}
\hline \multicolumn{2}{|c|}{ Grade level } & \multicolumn{2}{|c|}{ Age } & \multicolumn{2}{|c|}{ Years } & \multicolumn{2}{|c|}{ Region } \\
\hline Grades & $\%(n)$ & Range & $\%(n)$ & Range & $\%(n)$ & & $\%(n)$ \\
\hline $1-3$ & $14.6(20)$ & $20-30$ & $29.2(40)$ & $0-5$ & $27.7(38)$ & Seoul & $30.7(42)$ \\
\hline $4-6$ & $33.6(46)$ & $31-40$ & $43.8(60)$ & $6-10$ & $27.7(38)$ & Capital area & $48.2(66)$ \\
\hline $7-9$ & $16.8(23)$ & $41-50$ & $21.2(29)$ & $11-15$ & $20.4(28)$ & East and middle & $2.2(3)$ \\
\hline $10-12$ & $29.9(41)$ & $>50$ & $3.6(5)$ & $16-20$ & $10.9(15)$ & Southeast & $8.0(11)$ \\
\hline Specialist & $5.0(7)$ & No response & $2.2(3)$ & $21-25$ & $8.0(11)$ & Southwest & $10.9(15)$ \\
\hline & & & & $\geq 26$ & $4.4(6)$ & & \\
\hline
\end{tabular}

4.1. The Survey. The survey was adapted from the Survey of Technology Use in Literacy and Language Arts (STULLA), a rigorously developed and validated instrument used to determine perceptions about integrating ICTs into literacy instruction among teachers in the United States [12, 13]. For the South Korean survey, the following scales from the STULLA were selected: extent of ICT integration, perceived importance of ICT integration, and perceived obstacles to integration. These scales were selected because the other scales in the STULLA were not directly relevant to the research questions investigated in the current study. Cronbach alphas for these scales based on responses from the South Korean teachers were, respectively, .933, .858, and .867, indicating that the scales had acceptable internal consistency. Items providing demographic data (e.g., grade level taught and teaching experience) and inquiring about the availability of technology and technical support were also imported from the STULLA.

All relevant items associated with these main constructs were translated into Korean. Minor changes to the survey items were made to accommodate linguistic, cultural, and situational differences as guided by Pena's recommendations for linguistic, functional, and cultural equivalence in crosscultural research [52]. Further, the lead author of this study is a citizen of South Korea and a native speaker of Korean. For example, the Korean language does not have a word that corresponds exactly to literacy. Thus, the phrase "literacy instruction" was replaced in Korean with what might be translated into English as "reading, writing, or language arts instruction." Before being finalized, the translated survey was sent to a pilot group of 30 Korean teachers who were invited to complete the survey and to provide feedback about any items that were unclear, any notable omissions, and so forth. The survey was revised based on their feedback, and their surveys were not used in the subsequent analysis. For example, we changed our inquiries about iPods to ask more broadly about personal media players since Korean teachers reported that iPods are not popular in South Korea. The final survey included 63 items using a Likert-scale, 13 multiple-choice items, and 8 open-ended items. It can be accessed at the following site: http://www.surveymonkey.com/s/JD3KHQJ, and its counterpart in the US study can be accessed at http://www.surveymonkey.com/s/T2QTGJ5. The US version of the survey was administered online to 1,441 literacy and language arts teachers, most of whom were members of the International Reading Association, the largest professional organization for literacy teachers and based in the USA. Additional information about the survey of teachers in the USA and the data from that survey incorporated into the present report can be found in previously published reports $[12,13]$.

4.2. Dissemination. An invitation to complete the survey was sent to literacy teachers who were enrolled or who had recently been enrolled, in a graduate program in education at one of five universities in South Korea. These universities and the teachers who attended them represented all of the major metropolitan and geographical areas of South Korea. Teachers received an invitation to complete the online survey through an email from one of five professors who had worked with one or more of the students, typically as an academic advisor. These professors were acquaintances of the first author who requested their assistance in disseminating the survey to literacy teachers. An email containing an electronic link to the survey was sent from the professors to individual teachers requesting their participation. After 21 days, a follow-up email was sent as a reminder to increase the rate of a response [53]. Although 163 respondents started a survey, 26 (15\%) surveys were omitted, because they were not complete, resulting in 137 usable surveys. The professors did not report how many of their current or former students were sent the email inviting participation; thus, it is not possible to determine response rate, although that lack of data has been argued to be an acceptable limitation of online surveys [54].

4.3. Participants and Demographic Data. Respondents' grade level taught, age, teaching experience, and geographical region are summarized in Table 1 . All grade levels were represented, although there were fewer responses from teachers in the primary grades and in grades 7-9. Diverse levels of experience were also represented, although most respondents were approaching, or in the middle of their careers given the modal categories for age (31-40 years) and for experience (6-10 years). Likewise, diverse regions of South Korea are represented although most respondents lived in or near Seoul, the capital and largest city. Comparing this profile of participants with our previous work in the USA [13], there was one notable difference: language arts teachers responding to the US survey were skewed toward more experience $(22.3 \%$ with more than 26 years compared to $4.4 \%$ of the South Korean respondents). That discrepancy is likely explained by 


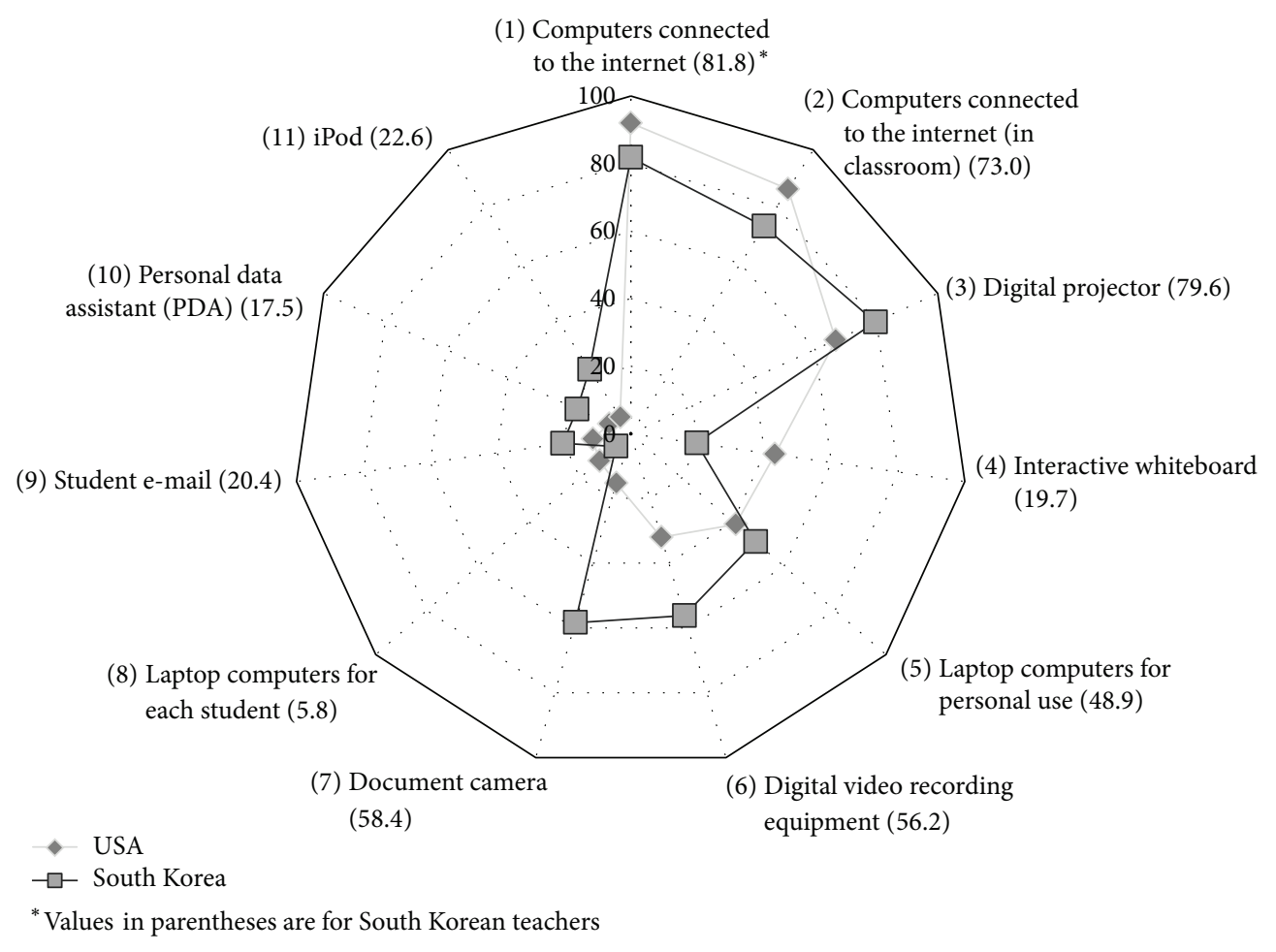

FIGURE 1: Percent of respondents indicating availability of technological tools and applications.

the different mechanisms used to disseminate the surveys, as noted in the methods section (i.e., South Korean respondents were enrolled or recently enrolled in graduate program).

4.4. Data Analysis. Multiple-choice and Likert-scale items were analyzed using descriptive statistics. In our previous work, we used data from literacy and language arts-teachers in the USA ( $n=1441)$ to conduct a path analysis testing a hypothesized model that predicted the level of integrating ICTs into instruction [13]. However, that approach was not appropriate for the current data, because, although respondents were arguably representative of the population of language arts teachers in South Korea, there were too few participants $(n=137)$ to warrant such analysis.

An open-ended question was used to examine how teachers define and conceptualize integration. Teachers were asked: "What do you think it looks like to integrate digital technology into reading, writing or language arts instruction? Give as many examples as you can." These open-ended responses were analyzed using a content analysis approach [55], with an a priori coding scheme derived from the parallel study of US teachers [13]. Particularly, Hutchison and Reinking [13] used an emergent coding scheme, which produced the following categories related to teachers' conceptualizations of integration: presentation tools, research, supplement or replacement for existing materials and instruction, enhancement tool and building block for background information, computer as tutor, student interaction, alternative format reading and texts, enhancing the instructional environment, and writing. Initial coding was conducted separately by two native speakers of Korean and indicated that all responses from the Korean survey fit into the a priori coding scheme. Although no new categories emerged, one category from the a priori coding scheme was not used. There were no responses from Korean teachers that fit into "computer as tutor" category. We believe that this difference could be due to cultural differences or due to the smaller sample size for the Korean survey. Each of the two coders coded all of the data and a few instances of disagreement between the two coders. However, all disagreements in coding were resolved through discussion.

\section{Results}

5.1. Access to Technology. Access to technology may affect level and type of integration. Thus, the survey asked teachers to report the availability of various technological tools and applications for using ICTs. From a list, respondents checked the tools that were available for them to use in their instruction. There was also an open-text box to report any tools not listed, which prompted 10 responses distributed as follows: smart phones (6), Ipad (2), and Internet TV (2). These responses point to the continually shifting diversity of ICTs available and how data, such as reported here, are necessarily transitory. The percentages (in parentheses) of respondents indicating the availability of specific technological tools are shown in Figure 1, which also shows the pattern of responses when compared to teachers in the US survey. 


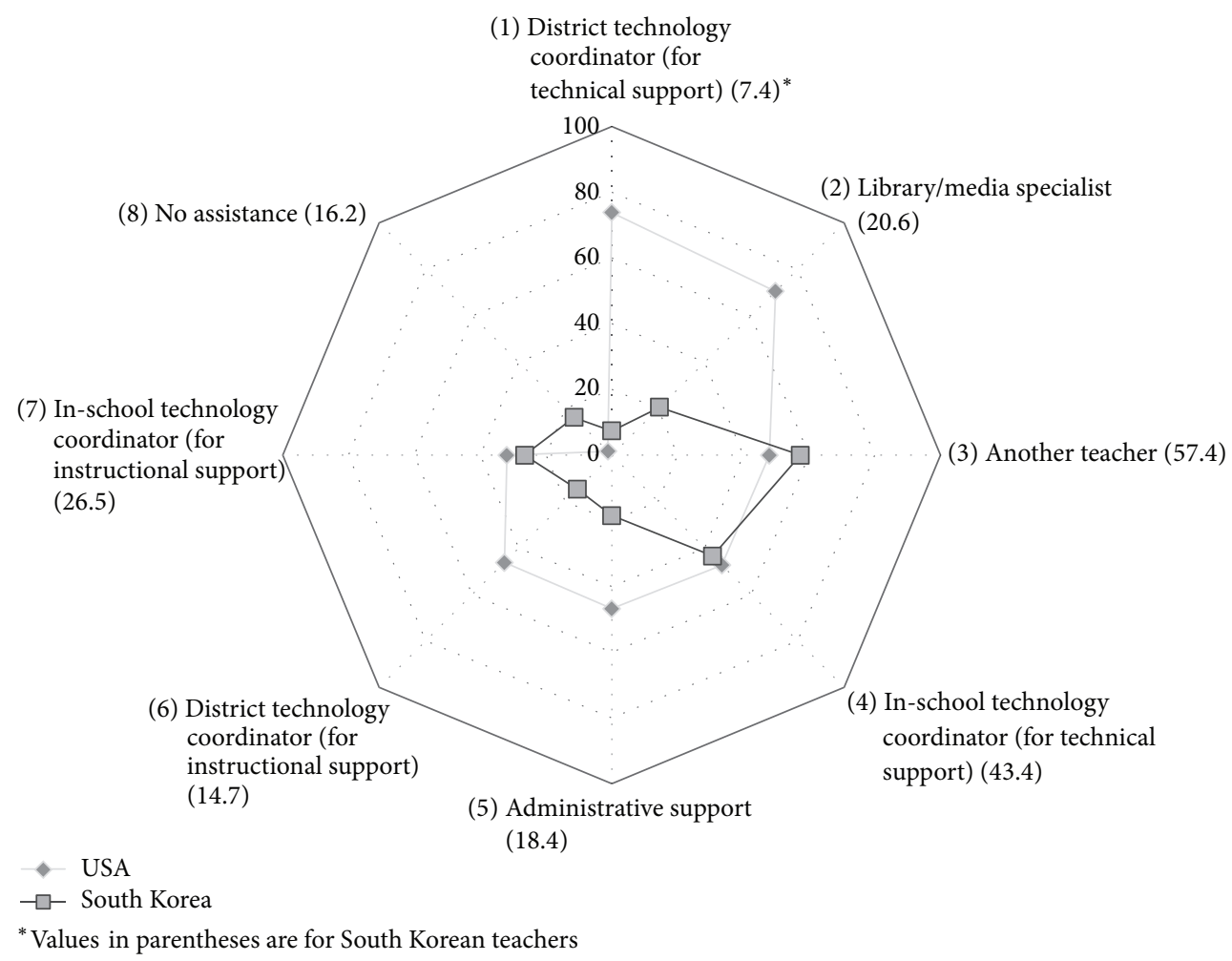

FIgURE 2: Percent of respondents indicating availability of technical support.

Overall, South Korean teachers report relatively high availability $(>75 \%)$ for computers connected to the Internet, digital projectors and recording equipment, document cameras, and low availability $(<25 \%)$ for personal media players, student laptops, interactive whiteboards, and email for students. This profile is consistent with educational reform policies enacted in South Korea. For example, the high availability of document cameras and digital recording equipment is likely explained by their inclusion on a list of eligible equipment funded through the enacted schoolenhancement policies, whereas interactive white boards, which are relatively expensive, are not reported to be widely available and were not included in that initiative. With the exception of the latter technologies, the overall pattern of availability parallels teachers' responses in the USA.

5.2. Technological Support. Interestingly, as shown in Figure 2, South Korean language arts teachers reported much less access to technical support than did their counterparts in the USA. For example, 7.4\% of the South Korean teachers reported support from a district technology coordinator compared to $73.8 \%$ of the teachers in the USA. Instead, most of the South Korean teachers (57.4\%) indicated that technological support came from another teacher. One explanation may be that many South Korean teachers often share offices and have many opportunities to interact with colleagues about problems and challenges. Notably, less than one-third of the South Korean and the US teachers reported having access to in-school instructional support for using technology, although almost half of the US teachers reported that support available at the district level, whereas fewer than $20 \%$ of the South Korean teachers reported such support. That difference, as discussed subsequently, may be explained by the typical situation in Korea where a technology coordinator's role is primarily administrative.

5.3. Frequency of Use and Perceived Importance. Table 2 shows South Korean teachers reported frequency of using various ICTs and compares that data to how they rated the importance of those uses. The reported frequency and the reported importance used identical Likert scales $(0=$ not at all, $1=$ small extent, $2=$ moderate extent, and 3 = large extent). Of interest, is that for every item on the list, respondents rated importance higher than frequency of use. This finding parallels our data from the USA where teachers likewise rated importance of every use higher than frequency (see [12]). However, South Korean teachers, when compared to their counterparts in the USA, reported higher frequency of engaging in activities or purposes related to 21st century literacy skills and online reading comprehension (e.g., see $[30,56])$. We computed $t$-tests to determine if the differences in favor of the South Korean teachers were statistically significant with the following results: formulating questions to research online, $t(1576)=4.36, P<.01$; locating information online, $t(1576)=4.40, P<.01$; evaluating information online, $t(1576)=2.36, P<.05$; and synthesizing information, $t(1576)=7.03, P<.01$. Thus, for all of the skills related to 21st century literacy, the South Korean teachers 


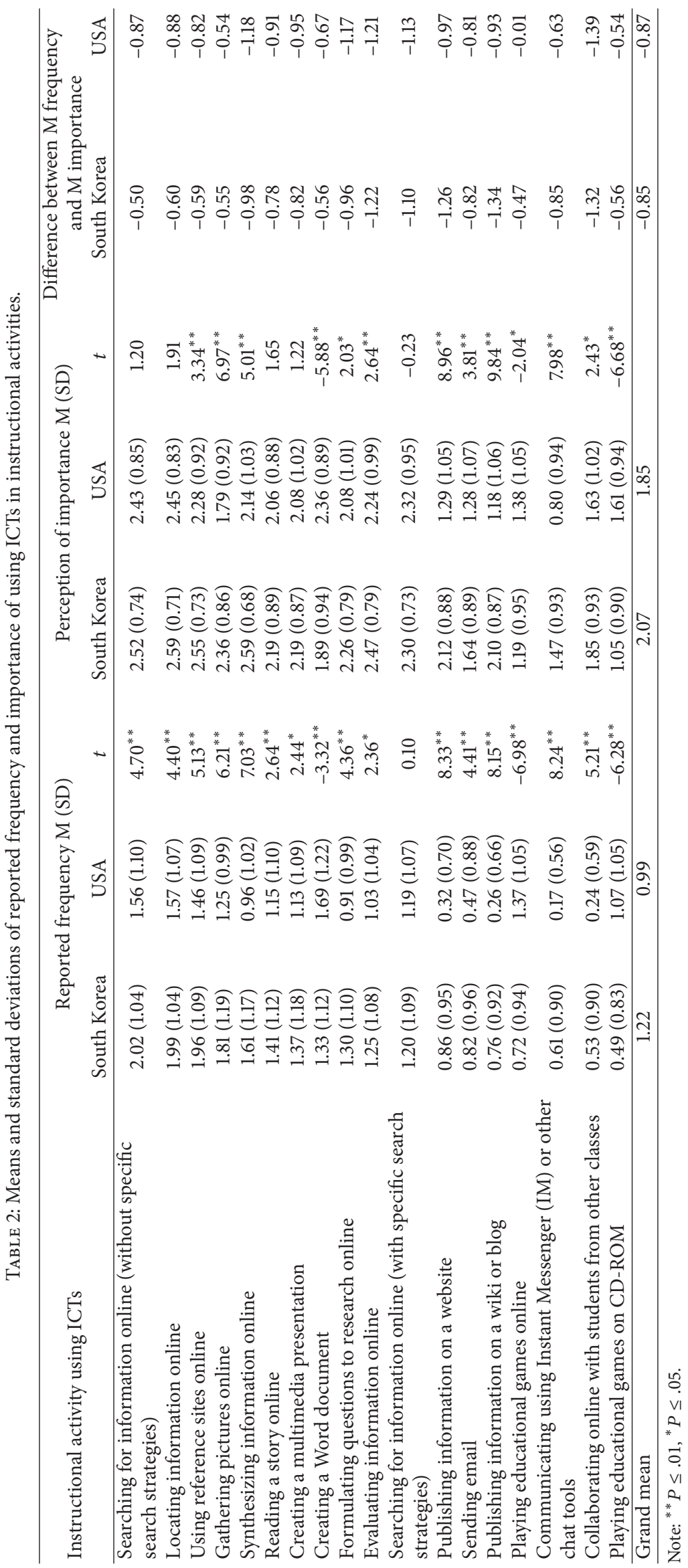


reported statistically more frequent use when compared to teachers in the USA.

5.4. Perceived Obstacles. Using a Likert scale, respondents indicated the extent to which they believed that each item on a list of 18 factors, which were derived from the literature and identified in previous research [12], was an obstacle to integrating ICTs into instruction (not at all $=0$, to a small extent $=1$, to a moderate extent $=2$, and to a large extent $=$ 3 ). Table 3 shows the pattern of responses and compares the pattern to our earlier data from teachers in the USA. With one exception (access to technology), South Korean literacy teachers perceived each factor to be a greater obstacle than their counterparts in the USA.

5.5. Conceptions of Technology Integration. On the survey, South Korean teachers responded to open-ended questions asking them to identify up to five examples that illustrate their conception of what it means to integrate ICTs into instruction. Table 4 compares the ten most frequent categories of responses coded, as described in the method section, for each population. There are notable differences between the responses of language arts teachers in the USA and in Korea. For example, half of the categories in each list do not overlap. The category with the most examples among the South Korean teachers was "supplement or replace current materials and instruction" (41\%). Less than half as many of the US teachers' responses (20\%) fell into that category, with their largest category of responses being "using presentation tools" $(38 \%)$. Other categories included in the ten most common categories for the South Korean teachers, but not for the US teachers, included enhancing communication ability (29\%), 21 st century preparation (19\%), and critical literacy (9\%), all of which suggest that South Korean teachers may be more focused on curricular rather than technological integration [13], which is a difference addressed further in the discussion section.

5.6. Correlations. As noted in the previous section describing our data analysis, there were too few respondents in the current study to conduct a path analysis. Nonetheless, we were interested in exploring whether certain factors and constructs that were related among teachers completing the US survey were similarly related among teachers in South Korea. In addition, we were interested in exploring relations that might be of particular interest from a cultural standpoint or that might inform instruction and education policy in South Korea (e.g., allocation of resources; professional development). Thus, we used correlational analyses appropriate for our sample size to explore possible relations among factors and constructs of interest. Since the data are not normally distributed, all subsequent correlations reported here are Spearman rank correlation coefficients for nonparametric data.

First, we computed correlations between the extent of integration and, respectively, the support for integration, availability of technology, and perceived obstacles to integration, all of which had resulted in statistically significant correlations in the US data. The values for the correlated variables were derived from composite scales as follows: (a) extent of integration $=$ mean frequency across the reported use of individual applications (see Table 2), (b) support for integration = mean number of sources for technical support, (c) availability of technology $=$ mean number of types of technology available, and $(\mathrm{d})$ perceived obstacles $=$ the mean reported extent to which items in a list were reported to be an obstacle to integration. South Korean teachers' extent of integration was correlated positively with support for integration $\left(r_{s}=.193, n=137, P<.05\right)$ and with the availability of technology $\left(r_{s}=.30, n=137, P<\right.$ $.01)$. However, the reported extent of integration and extent of obstacles were not correlated at a statistically significant level among the South Korean teachers, as it was among the US teachers where there was a statistically significant negative correlation. That is, for respondents in the USA, when the extent of obstacles reported was greater, the extent of integration was lower. That finding was not evident among participating teachers in South Korea.

Second, we correlated South Korean respondents' perceived importance for integration, as indicated by their report of how important they considered various instructional activities involving ICTs to be, with the following scales: (a) perceived obstacles, (b) support for integration, (c) availability of technology, and (d) extent of integration. All of these correlations, except support for integration, were again statistically significant in the US data. In the case of the Korean respondents, of these factors, only extent of integration was correlated at statistically significant levels $\left(r_{s}=\right.$ $0.32, n=137, P<.001)$. This positive correlation suggests that South Korean literacy and language arts teachers, like their counterparts in the USA, report greater integration of across various uses ICTs when they indicate higher levels of importance across those same uses (see Table 2 a list of types of integration).

\section{Discussion}

The present study provides a profile of South Korean literacy and language arts teachers' use of and perceptions about integrating ICTs into instruction. It also provides a point of comparison for a parallel survey conducted in the USA, revealing convergent and divergent patterns of responses when compared to our previous work. Thus, it adds interpretive depth to both sets of data, while giving specific direction for future research. In this section, we discuss what the present study reveals about integration of ICTs into literacy instruction in South Korea, the implications for education policy there, how the current data may clarify larger issues of technology integration across national and cultural borders, and how it informs next steps in our research.

South Korean literacy and language arts teachers' access to technology, as reported in this survey, is consistent with and likely reflects national education policy initiatives in the area of technology. Specifically, teachers reported having high levels of access to the computers connected to the Internet in classroom $(73 \%)$ and in school $(81.8 \%)$, digital projectors 


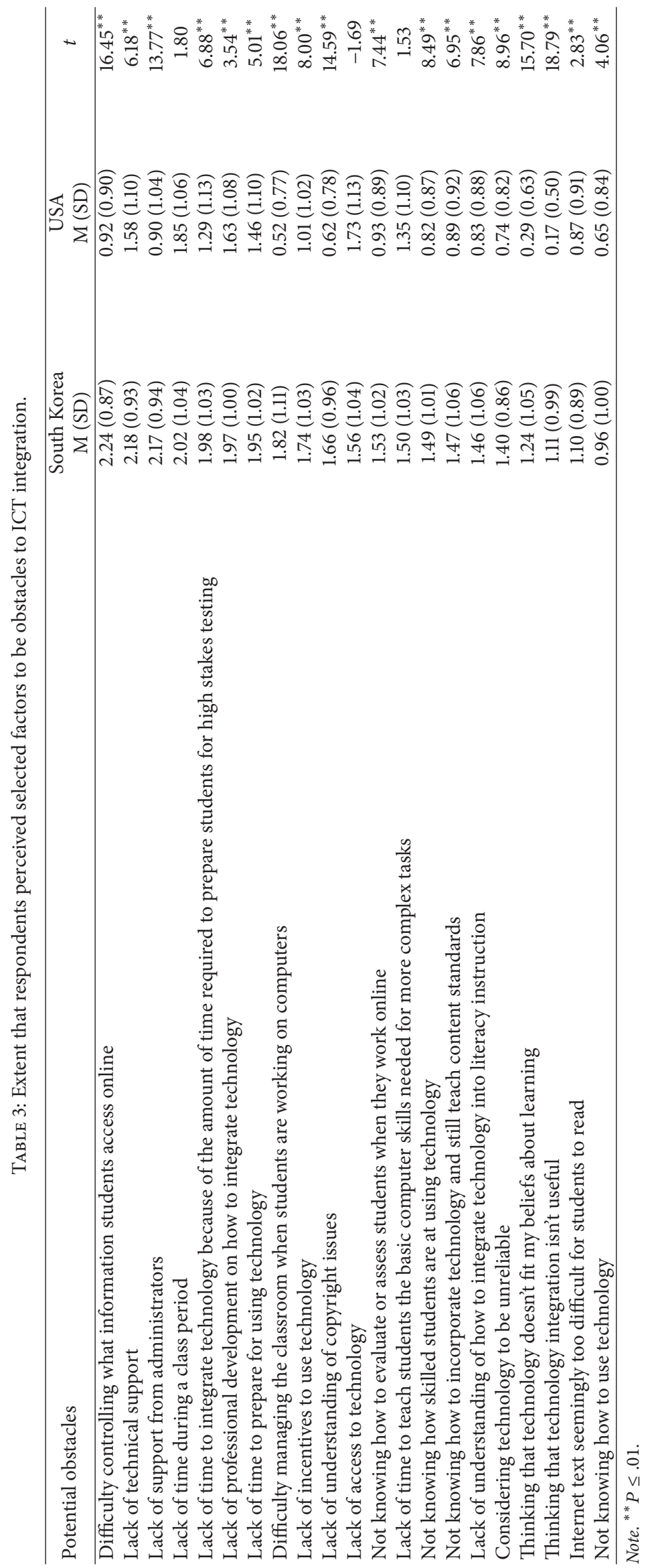


TABLE 4: Teachers' ranked perceptions of ICT integration from coding of open-ended responses.

\begin{tabular}{|c|c|c|c|c|}
\hline Rank & United States & $(\%)$ & South Korea & $(\%)$ \\
\hline 1 & Presentation tools & 38 & $\begin{array}{l}\text { Supplement or replacement for existing materials and } \\
\text { instruction }\end{array}$ & 41 \\
\hline 2 & Research & 23 & Enhancing the instructional environment & 32 \\
\hline 3 & $\begin{array}{l}\text { Supplement or replacement for existing materials and } \\
\text { instruction }\end{array}$ & 20 & Enhancing communication ability & 29 \\
\hline 4 & $\begin{array}{l}\text { Enhancement tool and building block for background } \\
\text { information }\end{array}$ & 16 & 21st century preparation & 19 \\
\hline 5 & Computer as tutor & 15 & Research & 17 \\
\hline 6 & Computer as publisher & 15 & Alternative format reading and texts & 13 \\
\hline 7 & Student interaction & 14 & Critical literacy & 9 \\
\hline 8 & Alternative format reading and texts & 13 & Writing & 8 \\
\hline 9 & Enhancing the instructional environment & 12 & Teacher resource & 8 \\
\hline 10 & Writing & 12 & $\begin{array}{l}\text { Enhancement tool and building block for background } \\
\text { information }\end{array}$ & 7 \\
\hline
\end{tabular}

(79.6\%), and digital video recording equipment (56.2\%), all of which have been funded as part of the government's education reform policies [43]. Similarly, the more limited access to interactive white boards (19.7\%), which are relatively expensive, likely reflects that this instructional tool was not included in funding initiatives, whereas in the USA, where there is more localized control, that tool is more often reported as available (43.1\%).

The reported minimal access to other tools and applications shown in Figure 1 (e.g., laptops for each student) parallel similarly minimal access reported by teachers in the USA with likely similar explanations such as the cost of the constituent technology or, in the case of email, concerns in many cultures about safeguarding students from inappropriate communications in school. Further, in both populations the level of access to technological tools and applications was correlated with the extent of integration. These data are consistent with Hutchison and Reinking's [13] previous findings that availability was a statistically significant mediating variable in a model predicting extent of integration. What is now needed is more refined data and analyses that connect the availability of specific technological tools and activities with particular types of integration.

Overall, South Korean teachers reported much less availability of technical support than teachers in the USA (Figure 2), which is likely explained, at least in part, by differences in administrative and organizational structure of the respective education systems. In US schools, specialized positions with responsibilities for assisting teachers with technological issues are common at the school and district level. These positions, when they exist in South Korea, are more administrative and related to overseeing and implementing national policies in the area of technology. The most prominent source of technical support reported by the South Korean teachers was another teacher (57.4\%). That finding may also reflect another distinctive feature of South Korean schools where teachers frequently share offices and thus have more opportunities to interact and to collaborate. If that interpretation can be substantiated, it suggests one possible mechanism that might be exploited to address technological issues and perhaps to increase integration.

Such support may be useful, because technical support was significantly correlated with level of integration, and half the respondents identified lack of technical support as an obstacle to integration to a moderate or great extent. Though ICT training for teachers was included in the ERP plans to integrate ICTs into the South Korean education system, policy makers there may want to consider exploring means to increase technological support as one avenue to increasing integration of ICTs into instruction, at least among literacy and language arts teachers. However, our more sophisticated analysis of the US data suggests a caveat to this interpretation. That is, in the US data, although level of support and extent of integration were significantly correlated, support was not a significant factor in a path analysis testing a model predicting extent of integration. Thus, more sophisticated analyses and more focused research methods may be needed to identify more clearly the extent to which technical support may be a prominent factor in increased integration among South Korean teachers.

Overall, South Korean teachers consistently reported somewhat greater frequency of using ICT applications and activities than their counterparts in the USA (see Table 2). However, a notable exception was on the two items referring to educational games. That exception may reflect a cultural difference consistent with Kweon's national survey of parents, teachers, and students in South Korea [57], which indicated ambivalence and some negative attitudes toward educational games, particularly among some segments of the population.

Further, the greatest differences in favor of the South Korean teachers were on those items reflecting 21st century literacy skills such as locating, evaluating, and synthesizing information on the Internet. Thus, despite reporting much less technical support than their counterparts in the USA, South Korean teachers report using ICTs more frequently in their instruction. These data raise further questions about 
the role of technical support in influencing actual integration of ICTs into literacy instruction and suggests that other factors may play a more prominent role given that South Korean teachers reported higher levels of integration despite much less official sources of support. Specific ERP plans aimed at increasing ICTs in the education system including government policy mandating that ICTs be integrated into $10 \%$ of instructional activities [49] may also explain these data. We intend to explore these possible explanations in subsequent research using focused interviews guided by data from the present study.

It is noteworthy that South Korean teachers rated 17 of the 18 obstacles to integration (see Table 3 ) derived from the literature [12] to be obstacles to a greater extent than the teachers in the USA. Yet, despite that obstacles were rated as more problematic among the Korean teachers, they reported using ICTs more frequently than teachers in the USA. Further, as was the case in our previous work in the USA, the extent of barriers identified as problematic was not significantly correlated with extent of integration overall. Thus, for both populations, the greater the perception that there are obstacles and challenges to integration apparently had little, if any, bearing on the extent of integration. Nonetheless, the obstacles South Korean teachers reported being problematic to the greatest extent were students' access to the Internet and administrative support. Lack of access to the Internet, in this instance, may have been interpreted as safe and appropriate access to relevant sites, given that $81.1 \%$ of the teachers reported having access to the Internet. It is not clear what respondents may have meant in identifying administrative support as a prominent obstacle, but policy makers in South Korea should perhaps note this finding. We intend to pursue both of these obstacles in greater depth in subsequent interviews with a sample of the respondents to this survey.

The largest category of the South Korean teacher's openended responses indicating their definitions of integrating ICTs was "supplement or replace current materials and instruction" (41\%). Less than half as many of the US teachers' responses (20\%) fell into that category, with their largest category of responses being "using presentation tools" (38\%). Other categories included in the ten most common categories for the South Korean teachers, but not in the top 10 categories for the US teachers, included enhancing communication ability (29\%) and critical literacy (9\%). These data suggest that South Korean literacy and language arts teachers, more than their counterparts in the USA, define integration of ICTs in curricular, rather than technological, terms. That is, teachers in the USA tended to view using the technologies associated with ICTs as representing integration, whereas Korean teachers tended to view integration as supplementing or replacing existing curriculum and instruction. That difference may be important, because in the US data, such beliefs, despite being mediated through several other variables, predicted levels of integration [13]. It is unclear from the present data what may account for this difference. Follow-up interviews with respondents similar to those in this study should help clarify reasons for this difference.

The correlational evidence from the present study reinforces the mounting evidence that integrating technology into instruction is more likely to occur when teachers believe that it is important to do so $[7,13,33,36,38,58]$. It also suggests that this conclusion transcends national and cultural boundaries. Thus, it is becoming clearer that teachers' beliefs are an important factor, not only in explaining the extent of integration, but as a potentially key focus for increasing integration. However, as the present investigation suggests, literacy and language arts teachers in South Korea and in the USA conceptualize differently what most comprises integration of ICTs into instruction. The relation between beliefs about importance, conceptualizations of what constitutes integration of ICTs (e.g., technological versus curricular), and extent of use merits more study.

Nonetheless, the findings, interpretations, and conclusions pertaining to this study are subject to limitations. The sample of respondents was not random and the response rate is unknown, although these are considered acceptable limitations in online survey research [59]. In addition, despite careful attention to creating a parallel translation, linguistic and cultural differences may have altered the meaning and thus the understanding of and responses to the items on the respective surveys. Thus, direct comparisons between the USA and South Korean data must be made cautiously.

Despite these limitations, the present investigation provides a preliminary examination of Korean teachers' perceptions about integrating ICTs into literacy instruction. It also provides a cross-cultural reference point that adds clarity to our previous work in the USA and suggests new directions for continued research in this area, including modifying the survey to address more directly the issues raised and the interpretations offered here. The survey that we have employed in our work or a modified version of it that reflects linguistic and cultural difference may be useful to investigate teachers' perceptions of integrating ICTs into literacy instruction in other countries and cultures. Most importantly, the data reported here help clarify trends and issues that inform further research using more focused methodologies such as interviews and observational data. We invite other researchers to join us in using it accordingly.

\section{Conflict of Interests}

The authors declare that there is no conflict of interests regarding the publication of this paper.

\section{References}

[1] S. E. Cha, S. J. Jun, D. Y. Kwon et al., "Measuring achievement of ICT competency for students in Korea," Computers \& Education, vol. 56, no. 4, pp. 990-1002, 2011.

[2] J. Coiro, M. Knobel, C. Lankshear, and D. J. Leu, "Central issues in new literacies and new literacies research," in Handbook of Research on New Literacies, J. Coiro, M. Knobel, C. Lankshear, and D. J. Leu, Eds., Taylor \& Francis, New York, NY, USA, 2008.

[3] J. Pulkkinen, "Cultural globalization and integration of ICT in education," in Educational Technology: Opportunities and Challenges, K. Kampulainen, Ed., Oulu University Press, Oulu, Finland, 2007. 
[4] C. Dede, "Emerging influences of information technology on school curriculum," Journal of Curriculum Studies, vol. 32, no. 2, pp. 281-303, 2000.

[5] J. Voogt and H. Pelgrum, "ICT and curriculum change," Human Technology, vol. 1, no. 2, pp. 157-175, 2005.

[6] R. Sutherland, V. Armstrong, S. Barnes et al., "Transforming teaching and learning: embedding ICT into everyday classroom practices," Journal of Computer Assisted Learning, vol. 20, no. 6, pp. 413-425, 2004.

[7] P. A. Ertmer, "Teacher pedagogical beliefs: the final frontier in our quest for technology integration?" Educational Technology Research and Development, vol. 53, no. 4, pp. 25-39, 2005.

[8] D. Reinking, L. D. Labbo, and M. C. McKenna, "From assimilation to accommodation: a developmental framework for integrating digital technologies into literacy research and instruction," Journal of Research in Reading, vol. 23, no. 2, pp. 110-122, 2000.

[9] D. Reinking, "Valuing reading, writing, and books in a posttypographic world," in The History of the Book in America, D. P. Nord, J. S. Rubin, and M. Schudson, Eds., vol. 5, pp. 485-502, University of North Carolina Press, Chapel Hill, NC, USA, 2009.

[10] D. Reinking, "An outward, inward, and school-ward overview of interactive communication technologies across the literacy landscape," in The International Handbook of English, Language and Literacy Teaching, D. Wyse, R. Andrews and, and J. Hoffman, Eds., pp. 328-341, Routledge, New York, NY, USA, 2010.

[11] D. Leu, "New literacies, reading research, and the challenges of change: a deictic perspective," in Proceedings of the 55th Yearbook of the National Reading Conference, J. Hoffman, D. Schallert, M. Fairbanks, J. Worthy, and B. Malloch, Eds., pp. 120, Oak Creek, Wis, USA, 2006.

[12] A. Hutchison and D. Reinking, "A national survey of barriers to integrating information and communication technologies into literacy instruction," in Proceedings of the 59th yearbook of the National Reading Conference, R. Jimenez, V. Risko, M. Hundley, and D. Rowe, Eds., pp. 230-243, Milwaukee, Wis, USA, 2010.

[13] A. Hutchison and D. Reinking, “Teachers' perceptions of integrating information and communication technologies into literacy instruction: a national survey in the United States," Reading Research Quarterly, vol. 46, no. 4, pp. 312-333, 2011.

[14] C. Richards, "From old to new learning: global imperatives, exemplary Asian dilemmas and ICT as a key to cultural change in education," Globalisation, Societies and Education, vol. 2, no. 3, pp. 337-353, 2004.

[15] D. Leu and D. Reinking, "Bringing insights from reading research to research on electronic learning environments," in Cognitive Aspects of Electronic Text Processing, H. Van Oostendorp and S. De Mul, Eds., pp. 43-75, Ablex Publishing Company, Norwood, NJ, USA, 1996.

[16] J. E. Mceneaney, "Agent-based literacy theory," Reading Research Quarterly, vol. 41, no. 3, pp. 352-371, 2006.

[17] D. Reinking, "Computers, reading, and a new technology of print," in Reading and Computers: Issues for Theory and Practice, D. Reinking, Ed., Computers and Education Series, pp. 3-23, Teachers College Press, New York, NY, USA, 1987.

[18] D. Reinking, "Differences between electronic and printed texts: an agenda for research," Journal of Educational Multimedia and Hypermedia, vol. 1, no. 1, pp. 11-24, 1992.

[19] D. Reinking, "Synthesizing technological transformations of literacy in a post typographic world," in Handbook of Literacy and Technology: Transformations in a Post-Typographic World, D. Reinking, M. C. McKenna, L. D. Labbo, and R. D. Kieffer, Eds., pp. 11-30, Lawrence Erlbaum Associates, Mahwah, NJ, USA, 1998.

[20] D. Reinking, "Multimedia and engaged reading in a digital world," in Literacy and Motivation: Reading Engagement in Individuals and Groups, L. Verhoeven and C. E. Snow, Eds., pp. 195-221, Lawrence Erlbaum, Mahwah, NJ, USA, 2001.

[21] G. Kress, Literacy in the New Media Age, Routledge, London, UK, 2003.

[22] C. Lankshear and M. Knobel, "New technologies in early childhood literacy research: a review of research," Journal of Early Childhood Literacy, vol. 3, no. 1, pp. 59-82, 2003.

[23] A. Hutchison, B. Beschorner, and D. Schmidt-Crawford, "Exploring the use of the iPad for literacy learning," The Reading Teacher, vol. 66, no. 1, pp. 15-23, 2012.

[24] M. Knobel and C. Lankshear, "Studying new literacies," Journal of Adolescent and Adult Literacy, vol. 58, no. 2, pp. 97-101, 2014.

[25] K. A. Lawless and P. G. Schrader, "Where do we go now? Understanding research on navigation in complex digital environments," in Handbook of Research on New Literacies, J. Coiro, M. Knobel, C. Lankshear, and D. J. Leu, Eds., pp. 267-296, Taylor and Francis, New York, NY, USA, 2008.

[26] S. Zhang and N. K. Duke, "Strategies for internet reading with different reading purposes: a descriptive study of twelve good internet readers," Journal of Literacy Research, vol. 40, no. 1, pp. 128-162, 2008.

[27] D. Leu, C. K. Kinzer, J. Coiro, and D. W. Cammack, “Toward a theory of new literacies emerging from the internet and other information and communication technologies," in Theoretical Models and Processes of Reading, R. B. Ruddell and N. J. Unrau, Eds., pp. 1570-1613, International Reading Association, Newark, Del, USA, 5th edition, 2004.

[28] D. J. Leu, J. Castek, and D. Hartman, "Evaluating the development of scientific knowledge and new forms of reading comprehension during online learning," Final Report, North Central Regional Educational Laboratory, Learning Point Associates, 2005, http://homepages.uconn.edu/ jmc03014/ FinalNCRELReport.pdf.

[29] International Reading Association (IRA), Integrating Literacy and Technology into the Curriculum: A Position Statement of the International Reading Association, International Reading Association, Newark, Del, USA, 2002.

[30] International Reading Association (IRA), "New literacies and 21st-century technologies: a position statement of the international reading association," 2009, http://www.reading .org/general/AboutIRA/PositionStatements/21stCenturyLiteracies.aspx.

[31] R. A. Karchmer, “The journey ahead: thirteen teachers report how the internet influences literacy and literacy instruction in their K-12 classrooms," Reading Research Quarterly, vol. 36, no. 4, pp. 442-466, 2001.

[32] E. Stolle, "Teachers, literacy, and technology: tensions, complexities, conceptualizations, and practice," in 57th Yearbook of the National Reading Conference, Y. Kim, V. Risko, D. Comton et al., Eds., pp. 56-69, National Reading Conference, Oak Creek, Wis, USA, 2008.

[33] C. M. Clark and P. L. Peterson, "Teachers' thought processes," in Handbook of Research on Teaching, M. C. Wittrock, Ed., pp. 255-296, Macmillan, New York, NY, USA, 3rd edition, 1986.

[34] P. A. Ertmer and A. T. Ottenbreit-Leftwich, "Teacher technology change: how knowledge, confidence, beliefs, and culture 
intersect," Journal of Research on Technology in Education, vol. 42, no. 3, pp. 255-284, 2010.

[35] D. Palak and R. T. Walls, "Teachers' beliefs and technology practices: a mixed-methods approach," Journal of Research on Technology in Education, vol. 41, no. 4, pp. 417-441, 2009.

[36] M. Windschitl and K. Sahl, "Tracing teachers' use of technology in a laptop computer school: the interplay of teacher beliefs, social dynamics, and institutional culture," American Educational Research Journal, vol. 39, no. 1, pp. 165-205, 2002.

[37] W. J. Pelgrum, "Obstacles to the integration of ICT in education: results from a worldwide educational assessment," Computers and Education, vol. 37, no. 2, pp. 163-178, 2001.

[38] C. Hague and B. Williamson, "Digital participation, digital literacy, and school subjects. A review of the policies, literature and evidence," 2009, http://www.futurelab.org.uk/ sites/default/files/Digital_Participation_review.pdf.

[39] C. P. Lim and C. S. Chai, "Teachers' pedagogical beliefs and their planning and conduct of computer-mediated classroom lessons," British Journal of Educational Technology, vol. 39, no. 5, pp. 807-828, 2008.

[40] L. Darling-Hammond, The Flat World and Education, Teachers College Press, New York, NY, USA, 2010.

[41] G. J. Kim, "Education policies and reform in South Korea," in Secondary Education in Africa: Strategies for Renewal, pp. 2939, 2002.

[42] H. Kim, H. Choi, J. Han, and H.-J. So, "Enhancing teachers' ICT capacity for the 21st century learning environment: three cases of teacher education in korea," Australasian Journal of Educational Technology, vol. 28, no. 6, pp. 965-982, 2012.

[43] D. Ku, "A study on the problem analysis and improvements of dissemination of ICTS in school enhancement policies," The Korean Journal of Elementary Education, vol. 24, no. 1, pp. 225239, 2008 (Korean).

[44] United Nations Educational Scientific and Cultural Organization (UNESCO), Integrating ICTs into Education: Lessons Learned, UNESCO Asia and Pacific Regional Bureau for Education, Bangkok, Thailand, 2004.

[45] Organisation for Economic Co-operation Development (OECD), PISA 2006 Database, OECD, Paris, France, 2008.

[46] Ministry of Education Science and Technology, Guidelines for Information and Communications Technology Training in Elementary and Secondary Schools, MEST, Seoul, Republic of Korea, 2000.

[47] Ministry of Education; Science and Technology (MEST), Standardization and Curriculum Specification of ISST, MEST, Seoul, Republic of Korea, 2002.

[48] Ministry of Education, Science, and Technology (MEST), Guidelines for Information and Communications Technology Training in Elementary and Secondary Schools, Ministry of Education, Science and Technology, Seoul, Republic of Korea, 2005.

[49] Ministry of Education; Science and Technology (MEST), Adapting Education to the Information Age : A White Paper, 2002.

[50] Ministry of Education Science and Technology, Adapting Education to the Information Age: White Paper, MEST, Seoul, Republic of Korea, 2011.

[51] J. Baumann and J. Bason, "Survey research," in Literacy Research Methodologies, N. K. Duke and M. H. Mallette, Eds., pp. 404426, The Guilford Press, New York, NY, USA, 2nd edition, 2011.
[52] E. D. Peña, "Lost in translation: methodological considerations in cross-cultural research," Child Development, vol. 78, no. 4, pp. 1255-1264, 2007.

[53] S. D. Crawford, M. P. Couper, and M. J. Lamias, "Web surveys: perceptions of burden," Social Science Computer Review, vol. 19, no. 2, pp. 146-162, 2001.

[54] B. K. Kaye and T. J. Johnson, "Research methodology: taming the cyber frontier: techniques for improving online surveys," Social Science Computer Review, vol. 17, no. 3, pp. 323-337, 1999.

[55] K. Neuendorf, The Content Analysis Guidebook, Sage, Thousand Oaks, Calif, USA, 2002.

[56] D. E. Leu, D. Reinking, A. Carter et al., "Defining online reading comprehension: using think-aloud verbal protocols to refine a preliminary model of Internet reading comprehension processes," in Proceedings of the Annual Meeting of the American Educational Research Association, Chicago, Ill, USA, 2007.

[57] H. Kweon, “Korean elementary school teachers', students', and parents' perceptions of educational functions of digital games," The Korean Journal of Elementary Education, vol. 17, no. 3, pp. 323-337, 2008 (Korean).

[58] B. C. Bruce and A. Rubin, Electronic Quills: A Situated Evaluation of Using Computers for Writing in Classrooms, Technology in Education Series, Lawrence Erlbaum Associates, Hillsdale, NJ, USA, 1993.

[59] V. M. Sue and L. A. Ritter, Conducting Online Surveys, Sange, Thousand Oaks, Calif, USA, 2007. 

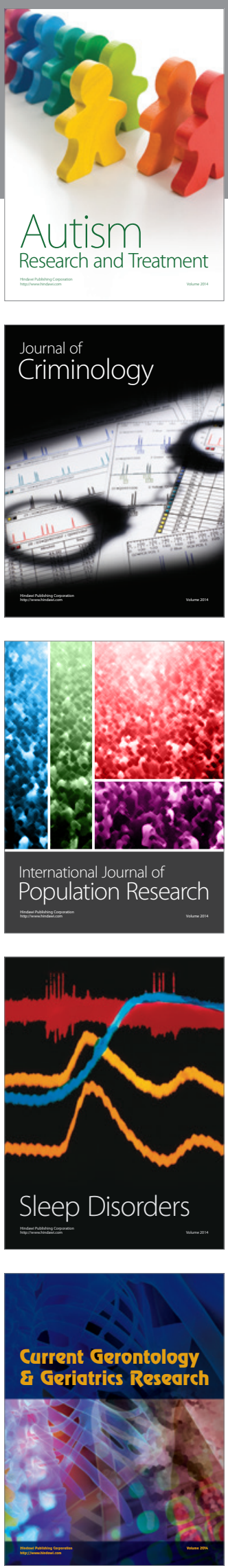
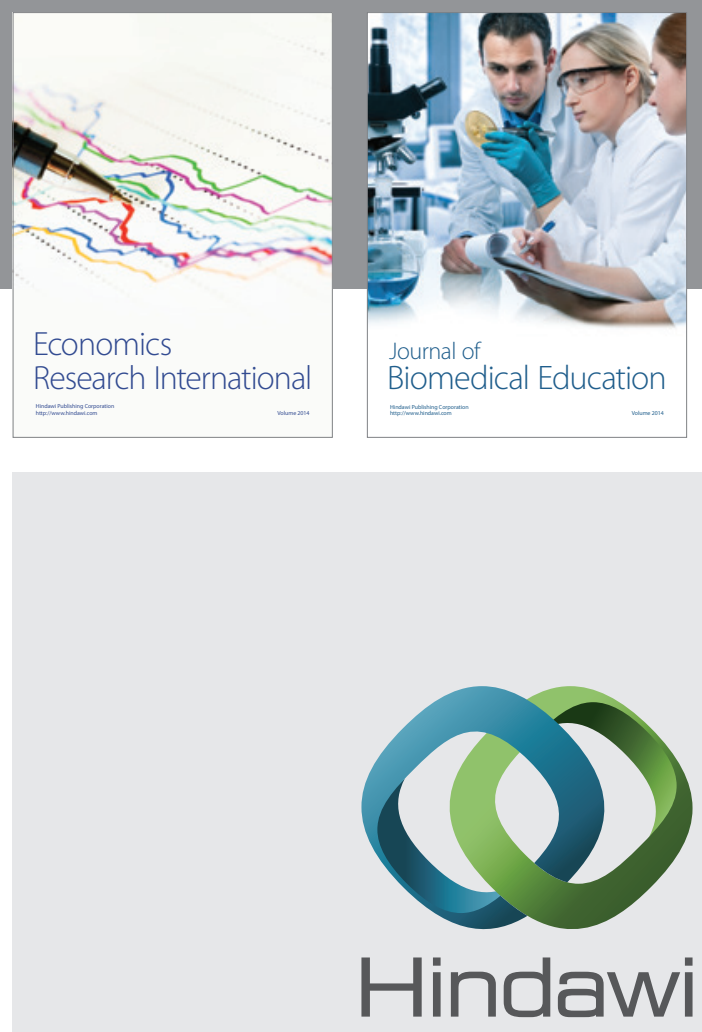

Submit your manuscripts at

http://www.hindawi.com
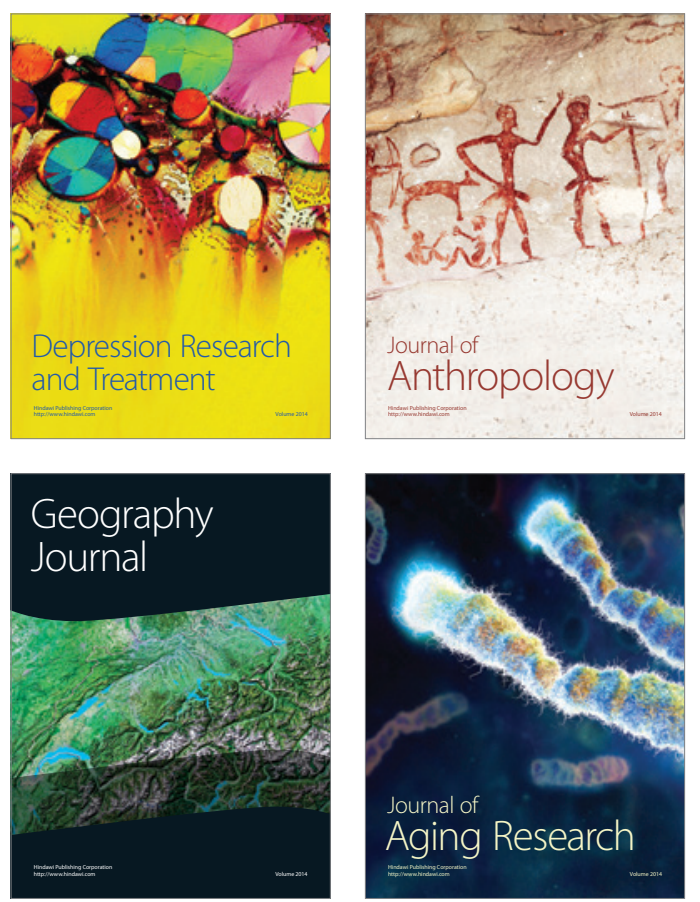
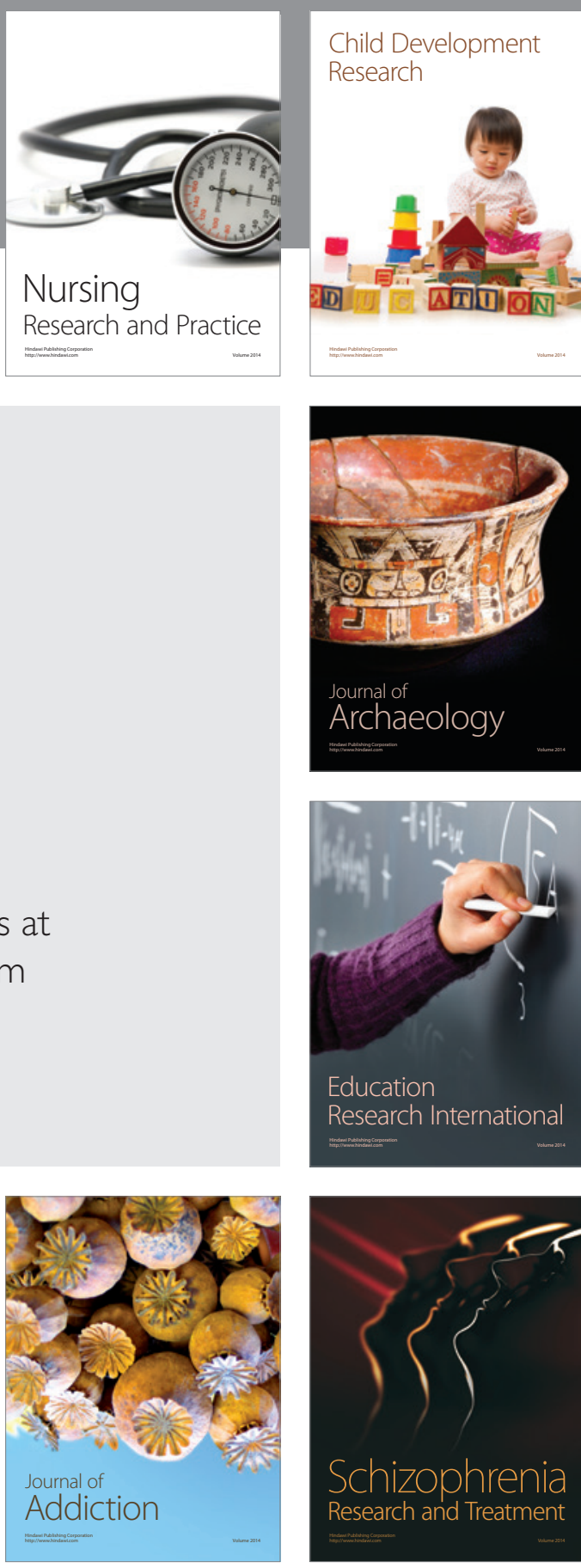

(D)
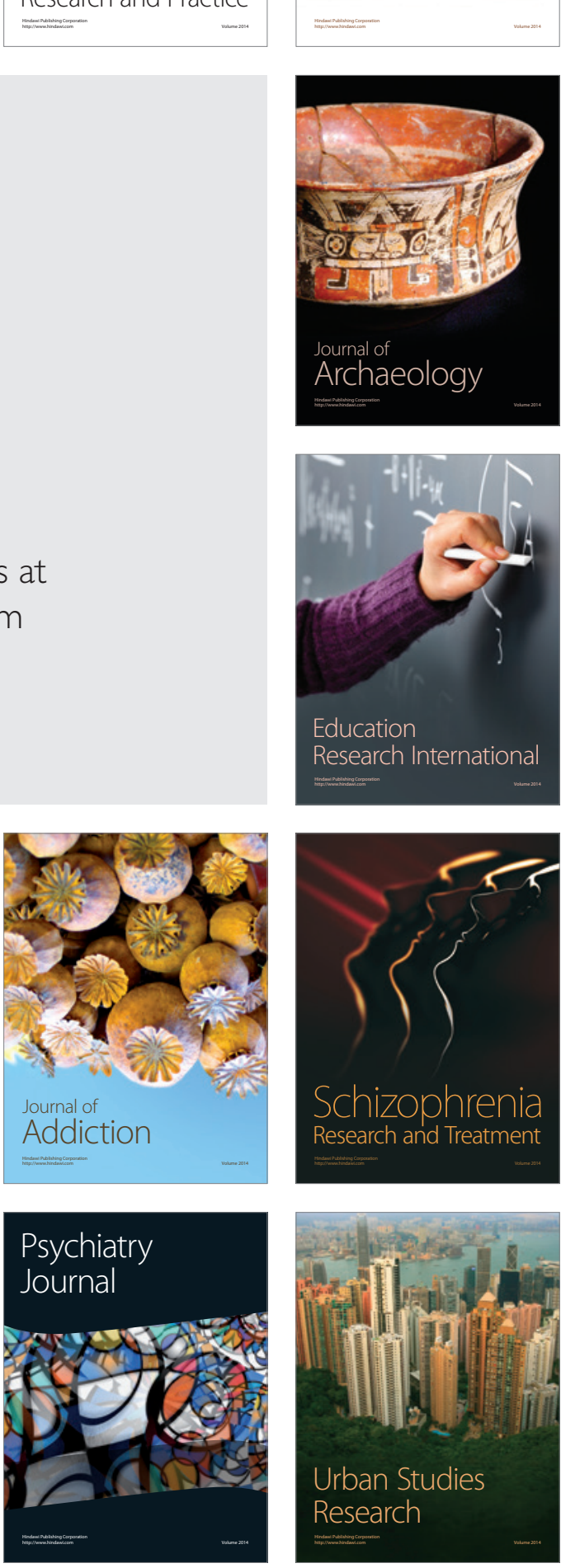